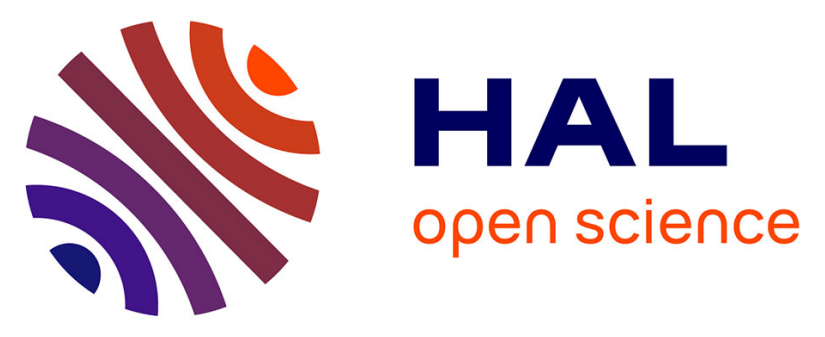

\title{
Outcomes of first-line endoscopic management for patients with sigmoid volvulus
}

Lucille Quénéhervé, Caroline Dagouat, Marianne Le Rhun, Enrique

Perez-Cuadrado Robles, Emilie Duchalais, Stanislas Bruley Des Varannes, Yann Touchefeu, Nicolas Chapelle, Emmanuel Coron

\section{To cite this version:}

Lucille Quénéhervé, Caroline Dagouat, Marianne Le Rhun, Enrique Perez-Cuadrado Robles, Emilie Duchalais, et al.. Outcomes of first-line endoscopic management for patients with sigmoid volvulus. Digestive and Liver Disease, 2019, 51, pp.386 - 390. 10.1016/j.dld.2018.10.003 hal-03486366

\section{HAL Id: hal-03486366 https://hal.science/hal-03486366}

Submitted on 20 Dec 2021

HAL is a multi-disciplinary open access archive for the deposit and dissemination of scientific research documents, whether they are published or not. The documents may come from teaching and research institutions in France or abroad, or from public or private research centers.
L'archive ouverte pluridisciplinaire HAL, est destinée au dépôt et à la diffusion de documents scientifiques de niveau recherche, publiés ou non, émanant des établissements d'enseignement et de recherche français ou étrangers, des laboratoires publics ou privés.

\section{(ㄷ)(1) $\$$}

Distributed under a Creative Commons Attribution - NonCommercial| 4.0 International 


\section{Outcomes of first-line endoscopic management for patients with sigmoid volvulus}

Lucille Quénéhervé, $M D^{1}$; Caroline Dagouat, $M D^{1}$; Marianne Le Rhun, $M D^{2}$; Enrique PerezCuadrado Robles, $\mathrm{MD}^{3}$; Emilie Duchalais, MD, $\mathrm{PhD}^{1}$; Stanislas Bruley des Varannes, MD, $\mathrm{PhD}^{1}$; Yann Touchefeu, MD, PhD ${ }^{1}$; Nicolas Chapelle, $\mathrm{MD}^{1}$; Emmanuel Coron, MD, PhD ${ }^{1}$.

${ }^{1}$ Institut des Maladies de l'Appareil Digestif (IMAD), University Hospital of Nantes, Hôtel Dieu, place Alexis Ricordeau, 44000 Nantes, France

${ }^{2}$ Pôle de Gérontologie Clinique, University Hospital of Nantes, France

${ }^{3}$ Clinique Universitaire Saint Luc, Bruxelles, Belgique

\section{Corresponding author:}

Lucille Quénéhervé

Institut des Maladies de l'Appareil Digestif, IMAD

University Hospital of Nantes

Hôtel Dieu, 1 place Alexis Ricordeau, 44000 Nantes, France

Tel.: +33 (0) 240083152 - Cell: +33 (0) 622945975 - Fax: +33 (0) 240083154

lucille.queneherve@gmail.com

Conflict of interests: None declared.

Funding: This work received a grant (FARE) from the Société Nationale Française de Gastroentérologie (SNFGE).

Electronic word count: 2442 


\section{Abstract (200/200words)}

Background: Sigmoid volvulus is a common cause of colonic obstruction in old and frail patients. Its standard management includes the endoscopic detorsion of the colonic loop, followed by an elective sigmoidectomy to prevent recurrence. However, these patients are often poor candidates for surgery.

Aim: The aim of this study was to compare death rate between elective sigmoidectomy and conservative management following endoscopic detorsion for sigmoid volvulus.

Methods: The medical records of 83 patients undergoing endoscopic detorsion of a sigmoid volvulus from 2008 to 2014 were retrospectively reviewed. Patients were divided into two groups: 'Elective surgery' and 'No surgery'.

Results: Patients in the 'no surgery' group' ( $n=42)$ were older and had more loss of autonomy than in the 'elective surgery' group. Volvulus endoscopic detorsion was successful in $96 \%$ of patients with no complications. The median follow-up was 13 months ( 1 day-67 months). The death rate was $62 \%$ in the 'no surgery' group versus $32 \%$ in the 'elective surgery' group $(p=0.02)$. In the 'no surgery' group, $23 / 42$ of patients had volvulus recurrence. No recurrence occurred after surgery.

Conclusion: Elective surgery must be planned as soon as possible after the first episode of sigmoid volvulus. In frail patients, other options must be developed.

Key words: sigmoid volvulus; colonic surgery; endoscopic treatment; geriatrics 


\section{Introduction:}

Sigmoid volvulus is caused by the rotation of the sigmoid loop around its meso axis, which leads to a closed-loop obstruction. It is a severe condition, constituting one of the three leading causes of colonic obstruction (10\% of cases) with colonic adenocarcinoma (60\%) and diverticulitis $(10 \%)(1)$. Colonic necrosis and peritonitis are the two main risk factors for mortality. In Western Europe and North America, this condition affects mostly elderly and institutionalized individuals. Male patients account for the majority of cases (2-5). However, in Africa and India, volvulus represents the leading cause of colonic obstruction (50\%), but patients in these areas are usually young and healthy (6). The diagnosis is based on radiological examinations, either by X-rays or computed tomography (CT) scans. The sensitivity of X-ray findings for the diagnosis of sigmoid volvulus is $50-90 \%$, while CT scans have a sensitivity close to $100 \%$ and enable the detection of the mechanism and complications (7-9). The first-line emergency treatment relies on the endoscopic management of the volvulus. The endoscopic treatment consists of the detorsion of the loop using a flexible colonoscope, without any colonic preparation, and the temporary placement of a Faucher colorectal tube both to optimize colonic exsufflation and reduce the risk of early recurrence. The clinical success is high, ranging from 75 to $90 \%(4,7,10,11)$. In cases of complication or failure of the endoscopic treatment, surgery is required, consisting of sigmoid resection with or without primary anastomosis. However, emergency surgery carries a high risk of complications, leading to a mortality rate ranging from 25 to $50 \%(12-14)$. Another issue is to develop strategies that prevent recurrence after successful endoscopic detorsion. Indeed, the recurrence rate after endoscopic treatment is high, estimated to be $50-90 \%(12,15,16)$. The current paradigm in this 
situation is to perform prophylactic surgery in the absence of contra-indications in selected patients. However, even a scheduled prophylactic surgery (general resection of the sigmoid colon with primary anastomosis) is at risk in these frail patients. Another surgical alternative, surgical sigmoidopexy, was developed but failed at preventing sigmoid volvulus recurrence; thus, it cannot be recommended $(10,17,18)$.

Data are scarce regarding the management of sigmoid volvulus and outcomes in old and frail patients. Our aim was to compare outcomes between patients who were not operated on (the 'no surgery' group) and patients who had an elective surgery to prevent recurrence (the 'elective surgery' group) after endoscopic treatment of an episode of sigmoid volvulus, with death rate as our primary endpoint.

\section{Methods}

\subsection{Patients}

We screened all patients admitted for sigmoid volvulus at the University Hospital of Nantes (France) from January 2008 to November 2014 who had an emergency endoscopy in the adult digestive unit. There were no exclusion criteria.

\subsection{Endoscopic procedure}

Rectosigmoidoscopy was performed within 12 hours after admission without bowel preparation nor sedation using a standard videocolonoscope. The procedure was as follows: during careful progression within the colon, the two rotation points were untwisted, allowing 
the endoscope to reach the upstream part of the colon. Decompression was then performed until clinical improvement was noted by the examination of the patient's abdomen. A lubricated guide wire with a blunt distal end was introduced through the working channel of the colonoscope and placed in the left colon. The endoscope was then removed and a sigmoid Faucher tube was placed, usually in the left colon, after the application of lubricant. The entire procedure was performed without fluoroscopic control. The tube was fixed to the thigh of the patient using adhesive tape to be maintained up to 72 hours. Enemas were performed using the Faucher tube until its removal.

\subsection{Data collection}

Data were retrospectively collected by consulting the medical database of the University Hospital of Nantes (Clinicom software) and through phone calls to patient's relatives, treating physician or institution.

Demographic characteristics, medical history, endoscopic and surgical management, and events occurring during the follow-up were collected. The autonomy score AGGIR (Geriatric Autonomie Groups Resources Needs) was calculated for each patient, a score of 1 or 2 defining a severe loss of autonomy(19).

2.4 Endpoints and definitions 
Patients who had not been operated on at the end of the follow-up were classified into the 'no surgery' group. Patients who underwent a planned surgery to avoid recurrence were classified into the 'elective surgery' group.

The primary endpoint of the study was the death rate in both groups. The measured outcome was the ratio of deaths to patients who reached more than 3 months of follow-up. The secondary endpoints were initial failure, early recurrence, emergency surgery and late recurrence. The outcome for initial failure was the ratio of patients for whom abdominal decompression was not obtained after the initial endoscopy to all patients undergoing an endoscopic treatment. The outcome for early recurrence was calculated as the ratio of patients with a recurrence of the obstruction caused by sigmoid volvulus requiring endoscopic or surgical management during the 15 days following the initial endoscopic management, to all patients undergoing an endoscopic treatment. The outcome for emergency surgery was calculated as the ratio of patients undergoing surgical rescue either for threatening colonic necrosis, initial endoscopic failure or early recurrence to all patients undergoing an endoscopic treatment. The outcome for late recurrence was calculated as the ratio of patients with a recurrence of obstruction more than 15 days after the initial management, to patients who reached more than 3 months of follow-up.

\subsection{Statistical analysis}

Baseline characteristics were analyzed by calculating the means for continuous variables and frequencies and percentages for categorical variables. Comparisons between groups for baseline characteristics were calculated using Fisher's exact test or Student's t test when 
appropriate. A Chi-square test was calculated to compare frequencies of outcomes between groups. All statistical analyses were performed using GraphPad Prism software version 5.00 for Windows (GraphPad Software, Inc., La Jolla, Calif.). A p-value less than 0.05 was considered as statistically significant.

\section{Results}

\subsection{Patients' characteristics}

We screened 83 patients (50 males and 33 females) ranging in age between 15 and 99 years who had been treated for sigmoid volvulus. The flow chart is provided in Figure 1. All patients were admitted on an emergency basis due to abdominal pain and distension. Diagnosis was suggested by abdominal X-rays or a CT scan (Figure 2) and confirmed by endoscopy. Median follow-up was 13 months ( 1 day-67 months). Nine patients were lost to follow-up after 3 months. Nevertheless, we considered these patients for the analysis of initial failure, early recurrence and emergency surgery.

Among the patients whose data were available after 3 months, 25 (34\%) underwent an elective surgery during the follow-up at an average of $9 \pm 9$ months after the first episode of sigmoid volvulus and $1 \pm 2$ after the last episode of volvulus. Forty-two patients (57\%) had no surgery at the end of follow-up. Seven patients had an emergency surgery. During the same period, only one patient had a first-line surgery for a fecal peritonitis resulting from a perforation of a sigmoid volvulus. 
The mean age was $76 \pm 12$ and $61 \pm 23$ years in the 'no surgery' and in the 'elective surgery' group, respectively $(p=0.006)$. Patients were mostly men in both groups $(67 \%$ and $72 \%$; $p=0.788$ ). Patients of the 'no surgery' group and the 'elective surgery' group had a history of neurological impairment in $69 \%$ and $48 \%$ of cases $(p=0.121)$, were institutionalized in $62 \%$ and $32 \%$ of cases $(p=0.024)$ and had a severe loss of autonomy in $45 \%$ and $16 \%$ of cases $(p=0.018)$, respectively (Table 1$)$.

\subsection{Death rate}

Thirty-eight patients (51\%) died during the follow-up with a median follow-up of 12.5 months (0 days-55 months). In the 'no surgery' group and the 'elective surgery' group, 26 and 8 deaths occurred, respectively ( $p=0.018)$; among them, 19 and 6 patients, respectively, died from causes other than volvulus $(p=0.117)$.

\subsection{Initial failure, early recurrence and emergency surgery}

A Faucher tube was placed in the sigmoid colon of 76 patients (92\%). No complications of the endoscopic procedure were reported. Sigmoid volvulus detorsion failure occurred in 3 patients. Among them, the mean age was $86 \pm 7$ and 2 patients had a history of sigmoid volvulus. Mucosal lesions were described in 12 patients during the rectosigmoidoscopy. Among them, 6 had mild ischemic lesions, such as petechiae and mucosal edema, 1 had ulcerations without necrosis and 5 had necrotic lesions of the sigmoid mucosa. Three of the patients with digestive necrosis had emergency surgery, and two died from complications of necrosis. 
The early recurrence of the sigmoid volvulus occurred in 21 patients (25\%) with a median duration of 4 days (1-11 days) after the first detorsion.

Seven patients (8\%) underwent an emergency surgery. The mean age was $81 \pm 9$ years. Among them, 3 patients underwent a surgery for digestive necrosis, 1 because of a failure of the initial endoscopic treatment, with no evidence of digestive necrosis, 2 because of early recurrence and one for failure of endoscopic detorsion during the third episode of volvulus. Surgical procedures are described in Table 2. The adverse effects of the emergency surgery were death in 2 patients, evisceration in 1 patient, cardiogenic pulmonary edema in 1 patient and anastomotic stenosis in 1 patient. Ten patients underwent adverse effects in the elective surgery group, among them 2 underwent several complications and 2 died from causes related to volvulus. There was no significant difference in the complication rate between the 2 groups $(p=0.21)$. Surgical complications according to the Clavien-Dindo classification are reported in Table 3(20).

\subsection{Late recurrence}

Forty-seven patients (64\%) had at least one recurrence of sigmoid volvulus during the followup, with a median of 1 recurrence per patient (1-19). These recurrences led to rehospitalizations for a median duration of 10 days (1-88 days), resulting in a total of 581 days in all patients. In the 'no surgery' group, 21 patients (50\%) had at least one recurrence of sigmoid volvulus during the follow-up, with a median of 2 recurrences per patient (1-19). A history of early recurrence was not a risk factor for recurrence during the follow-up. There was no 
difference in the demographic characteristics between the patients who had recurrence and the patients who had no recurrence (Table 4). Patients who underwent an elective surgery had a median of 1 episode of sigmoid volvulus (1-5) before surgery. None of the patients had a recurrence after surgery.

\section{Discussion}

Our study reports the management and outcomes of acute sigmoid volvulus in clinical practice over a 6-year period in a single institution. In contrast to the Middle East and Africa, where series reach often more than 100 patients (21,22), data are scarce in Europe (23-27), highlighting the comparatively low incidence of the condition. Therefore, this work is important because it shows that this disease affects a population of frail, old and institutionalized patients who are at risk of volvulus recurrence and, generally, are poor candidates for surgery. In addition, our results suggest that endoscopic management is safe, since no complications were noted, but it remains a short-term solution. When elective surgery cannot be performed, recurrences are frequent and warrant a search for alternate solutions.

Patients were older and frailer in the 'no surgery' group, highlighting the reluctance to perform colonic surgery in this population. It is interesting to note that the high mortality in the "no surgery' group was mainly due to sigmoid volvulus, while the number of non-volvulus-related deaths was not significantly different in both groups.

Initial endoscopic treatment was effective in $94 \%$ of patients and safe, since no endoscopic complications occurred in this cohort. This emphasizes the efficacy of emergency 
sigmoidoscopy as a first-line treatment, provided that the patient is afebrile, hemodynamically stable and that imaging does not show any sign of complications. In contrast, immediate surgery was associated with a $29 \%$ post-operative mortality rate in our study and should be considered only in cases of complication. Nevertheless, $25 \%$ of our patients experienced an early recurrence of the sigmoid volvulus, i.e., occurring less than 15 days after the initial rectosigmoidoscopy, and $64 \%$ showed a recurrence during the follow-up. This high rate of recurrences was expected, as it is consistent with the European literature $(23,24)$, and this study highlights the need for prophylactic treatment. The young and less frail patients underwent an elective surgery during the follow-up, mostly sigmoid resection with primary colo-colic anastomosis. No difference in the complication rate was noted between patients who underwent an emergency surgery and patients who underwent an elective surgery, however, the small number of patients may have induced a loss of statistical power.

The main limit of our study stands in its retrospective design, which prevented the analysis of several parameters, such as the time from diagnosis or hospital admission to first-line endoscopic therapy or the impact of prophylactic measures after the first episode on the risk of recurrence. However, the median follow-up of our patients was 13 months, which enabled us to analyze their outcomes, especially mortality and recurrence. Only 9 patients $(11 \%)$ were lost to follow-up. It is also a relatively small sample size with a heterogeneous population. The number of patients included in 6 years is consistent with the low incidence of sigmoid volvulus in Western countries. However, our data are of interest since there are few recent data in Western countries to describe the phenotypic, social and demographic features of this disease. 
Additionally, few data are available about adverse effects and mortality rate of endoscopy and surgery in 'real-life' conditions.

Endoscopic sigmoidopexy might be a promising option for preventing recurrence in fragile patients. Indeed, our study shows that the mean number of recurrences among patients too old or too frail to undergo surgery and among patients who refused surgery was important $(3 \pm 4$ recurrences per patient). As Western populations are growing older, there is a need for a treatment for these patients. Indeed, recurrences in geriatric patients lead to rehospitalizations with decompensation of geriatric frailties (confusion, undernutrition) or to emergency surgery, which has high mortality and morbidity. An initial geriatric assessment would be relevant in patients with a first episode of sigmoid volvulus to select those who could benefit from a planned surgery, with a specialized geriatric follow-up. Percutaneous endoscopic colostomy performed in the sigmoid colon for the treatment of sigmoid volvulus seems promising for frail patients for which surgery seems unreasonable, especially if the colostomy could be used to exsufflate the colon at home. However, too few data are available to assess its safety and accuracy (28-32).

In conclusion, our data support the early management of sigmoid volvulus by endoscopy, which is successful in the vast majority of cases. However, due to early recurrence in approximately one-fourth of patients, elective surgery must be planned as soon as possible after the first episode of sigmoid volvulus. In frail patients, the development of other options, such as endoscopic sigmoidopexy, should be evaluated. 


\section{Acknowledgements:}

Lucille Quénéhervé thanks the DHU 2020 for their funding. Emmanuel Coron thanks the Société Nationale Française de Gastro-entérologie (SNFGE) for the FARE grant. 


\section{References}

1. Taourel P, Kessler N, Lesnik A, Pujol J, Morcos L, Bruel JM. Helical CT of large bowel obstruction. Abdom Imaging. 2003 Apr;28(2):267-75.

2. Halabi WJ, Jafari MD, Kang CY, Nguyen VQ, Carmichael JC, Mills S, et al. Colonic Volvulus in the United States: Trends, Outcomes, and Predictors of Mortality. Ann Surg. 2014 Feb 1;259(2):293-301.

3. Welch GH, Anderson JR. Acute volvulus of the sigmoid colon. World J Surg. 1987 Apr;11(2):258-62.

4. Ballantyne GH, Brandner MD, Beart RW, Ilstrup DM. Volvulus of the colon. Incidence and mortality. Ann Surg. 1985 Jul;202(1):83-92.

5. Swenson BR, Kwaan MR, Burkart NE, Wang Y, Madoff RD, Rothenberger DA, et al. Colonic volvulus: presentation and management in metropolitan Minnesota, United States. Dis Colon Rectum. 2012 Apr;55(4):444-9.

6. Sule AZ, Ajibade A. Adult large bowel obstruction: a review of clinical experience. Ann Afr Med. 2011 Mar;10(1):45-50.

7. Atamanalp SS. Treatment of sigmoid volvulus: a single-center experience of 952 patients over 46.5 years. Tech Coloproctology. 2013 Oct;17(5):561-9.

8. Levsky JM, Den El, DuBrow RA, Wolf EL, Rozenblit AM. CT findings of sigmoid volvulus. AJR Am J Roentgenol. 2010 Jan;194(1):136-43.

9. Burrell HC, Baker DM, Wardrop P, Evans AJ. Significant plain film findings in sigmoid volvulus. Clin Radiol. 1994 May;49(5):317-9.

10. Oren D, Atamanalp SS, Aydinli B, Yildirgan MI, Başoğlu M, Polat KY, et al. An algorithm for the management of sigmoid colon volvulus and the safety of primary resection: experience with 827 cases. Dis Colon Rectum. 2007 Apr;50(4):489-97.

11. Lou Z, Yu E-D, Zhang W, Meng R-G, Hao L-Q, Fu C-G. Appropriate treatment of acute sigmoid volvulus in the emergency setting. World J Gastroenterol. 2013 Aug 14;19(30):4979-83.

12. Safioleas M, Chatziconstantinou C, Felekouras E, Stamatakos M, Papaconstantinou I, Smirnis A, et al. Clinical considerations and therapeutic strategy for sigmoid volvulus in the elderly: a study of 33 cases. World J Gastroenterol. 2007 Feb 14;13(6):921-4.

13. Cirocchi R, Farinella E, La Mura F, Morelli U, Trastulli S, Milani D, et al. The sigmoid volvulus: surgical timing and mortality for different clinical types. World J Emerg Surg WJES. 2010 Jan 13;5:1. 
14. Grossmann EM, Longo WE, Stratton MD, Virgo KS, Johnson FE. Sigmoid volvulus in Department of Veterans Affairs Medical Centers. Dis Colon Rectum. 2000 Mar;43(3):414-8.

15. Yassaie $\mathrm{O}$, Thompson-Fawcett $\mathrm{M}$, Rossaak J. Management of sigmoid volvulus: is early surgery justifiable? ANZ J Surg. 2013 Jan;83(1-2):74-8.

16. Chung YF, Eu KW, Nyam DC, Leong AF, Ho YH, Seow-Choen F. Minimizing recurrence after sigmoid volvulus. Br J Surg. 1999 Feb;86(2):231-3.

17. Perrot L, Fohlen A, Alves A, Lubrano J. Management of the colonic volvulus in 2016. J Visc Surg. 2016 Jun;153(3):183-92.

18. Gordon-Weeks AN, Lorenzi B, Lim J, Cristaldi M. Laparoscopic-assisted endoscopic sigmoidopexy: a new surgical option for sigmoid volvulus. Dis Colon Rectum. 2011 May;54(5):645-7.

19. Vetel JM, Leroux R, Ducoudray JM. [AGGIR. Practical use. Geriatric Autonomy Group Resources Needs]. Soins Gerontol. 1998 Jun;(13):23-7.

20. Dindo D, Demartines N, Clavien P-A. Classification of surgical complications: a new proposal with evaluation in a cohort of 6336 patients and results of a survey. Ann Surg. 2004 Aug;240(2):205-13.

21. Maddah G, Kazemzadeh GH, Abdollahi A, Bahar MM, Tavassoli A, Shabahang H. Management of sigmoid volvulus: options and prognosis. J Coll Physicians Surg--Pak JCPSP. 2014 Jan;24(1):13-7.

22. Mnguni MN, Islam J, Manzini V, Govindasamy V, Zulu BMW, Clarke DL, et al. How far has the pendulum swung in the surgical management of sigmoid volvulus? Experience from the KwaZulu-Natal Teaching Hospitals and review of the literature. Colorectal Dis Off J Assoc Coloproctology G B Irel. 2012 Dec;14(12):1531-7.

23. Ifversen AKW, Kjaer DW. More patients should undergo surgery after sigmoid volvulus. World J Gastroenterol. 2014 Dec 28;20(48):18384-9.

24. Hougaard HT, Qvist N. Elective surgery after successful endoscopic decompression of sigmoid volvulus may be considered. Dan Med J. 2013 Jul;60(7):A4660.

25. Baker DM, Wardrop PJ, Burrell H, Hardcastle JD. The management of acute sigmoid volvulus in Nottingham. J R Coll Surg Edinb. 1994 Oct;39(5):304-6.

26. Bruzzi $M$, Lefèvre JH, Desaint $B$, Nion-Larmurier I, Bennis $M$, Chafai $N$, et al. Management of acute sigmoid volvulus: short- and long-term results. Colorectal Dis Off J Assoc Coloproctology G B Irel. 2015 Oct;17(10):922-8.

27. Mulas C, Bruna M, García-Armengol J, Roig JV. Management of colonic volvulus. Experience in 75 patients. Rev Espanola Enfermedades Dig Organo Of Soc Espanola Patol Dig. 
2010 Apr;102(4):239-48.

28. Tin K, Sobani ZA, Anyadike N, Serur A, Mayer I, Iswara K, et al. Percutaneous endoscopic sigmoidopexy using T-fasteners for management of sigmoid volvulus. Int J Colorectal Dis. 2017 Jul 1;32(7):1073-6.

29. López-Serrano A, Amurrio CA, Hervás J, Latorre P, Ortiz I, Polanco A, et al. Endoscopic treatment of recurrent sigmoid volvulus with colopexy assisted by T-fasteners and colostomy. Endoscopy. 2016;48 Suppl 1:E236-237.

30. Pinedo G, Kirberg A. Percutaneous endoscopic sigmoidopexy in sigmoid volvulus with Tfasteners: report of two cases. Dis Colon Rectum. 2001 Dec;44(12):1867-9; discussion 18691870.

31. Frank L, Moran A, Beaton C. Use of percutaneous endoscopic colostomy (PEC) to treat sigmoid volvulus: a systematic review. Endosc Int Open. 2016 Jul;4(7):E737-741.

32. Baraza W, Brown S, McAlindon M, Hurlstone P. Prospective analysis of percutaneous endoscopic colostomy at a tertiary referral centre. Br J Surg. 2007 Nov;94(11):1415-20. 
Figure legends:

\section{Figure 1: Study flow diagram}

Patients in the first-line surgery group had no endoscopy during management. Lost to follow-up was defined as a failure to achieve 3 months of follow-up. Patients in the emergency surgery group underwent surgical rescue for digestive necrosis or failure of initial endoscopic management. Patients in the 'elective surgery' group underwent planned surgery to prevent recurrences.

\section{Figure 2: CT scan images of sigmoid volvulus}

A) An abdominal CT scan scout image displaying the sigmoid loop, typically termed the 'coffee bean sign'. B) Sagittal cross-section displaying the 'whirl sign' figuring the torsion of the colon and its vessels. 


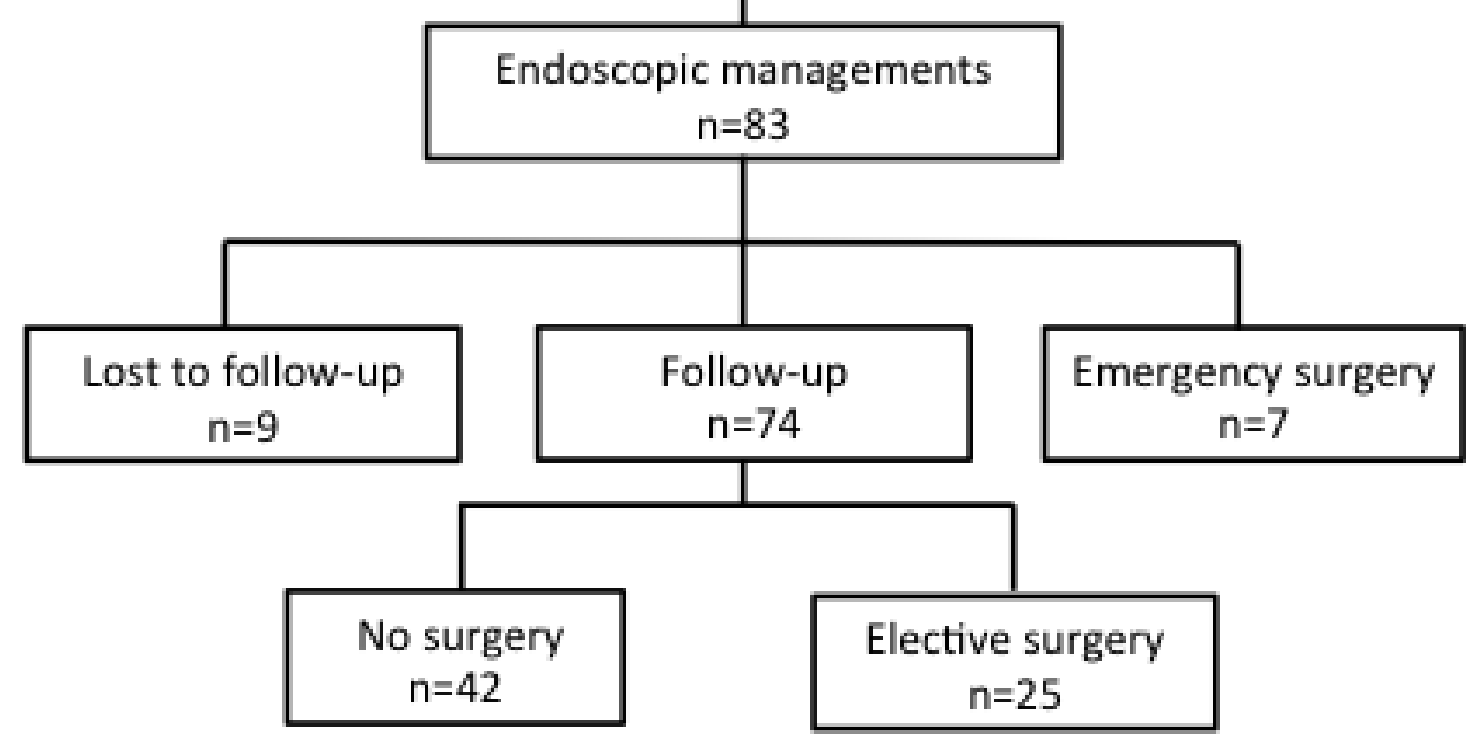




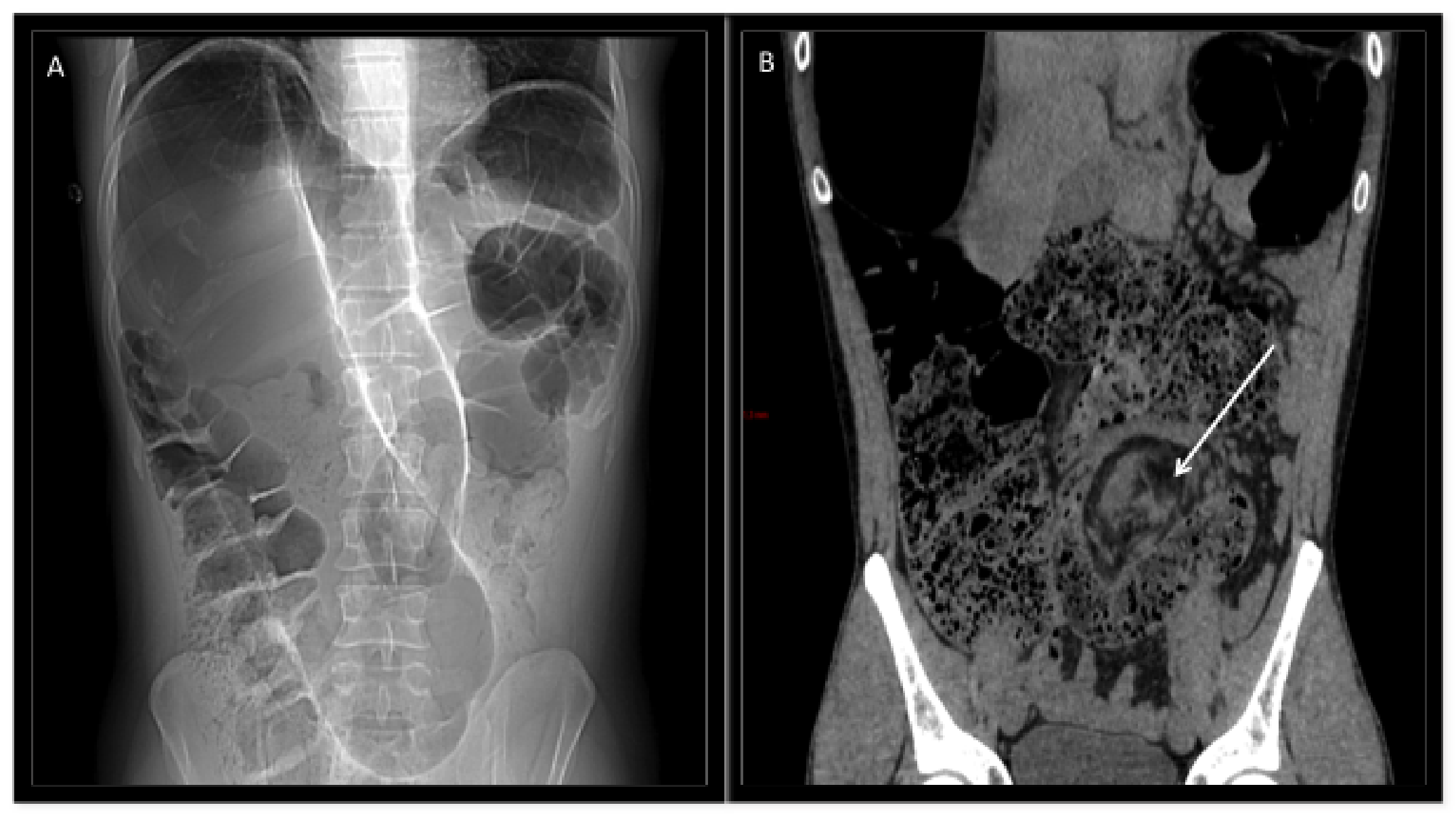




\section{Table 1: Patients' characteristics.}

\begin{tabular}{|c|c|c|c|}
\hline & $\begin{array}{l}\text { Total } \\
(n=83)\end{array}$ & $\begin{array}{l}\text { No surgery } \\
\text { group } \\
\quad(n=42)\end{array}$ & $\begin{array}{l}\text { Elective } \\
\text { surgery } \\
\text { group } \\
(n=25)\end{array}$ \\
\hline Mean age \pm SD (years) & $72 \pm 18$ & $76 \pm 12^{*}$ & $61 \pm 23^{*}$ \\
\hline \multicolumn{4}{|l|}{ Gender } \\
\hline Male & $50(60 \%)$ & $28(67 \%)$ & $18(72 \%)$ \\
\hline Institutionalized & $40(48 \%)$ & $26(62 \%)^{*}$ & $8(32 \%)^{*}$ \\
\hline $\begin{array}{l}\text { Severe loss of autonomy (AGGIR } \\
\text { score } 1 \text { or } 2 \text { ) }\end{array}$ & $27(33 \%)$ & $19(45 \%)^{*}$ & $4(16 \%)^{*}$ \\
\hline History of neurological impairment & $48(58 \%)$ & $29(69 \%)$ & $12(48 \%)$ \\
\hline $\begin{array}{l}\text { Neurovascular or } \\
\text { neurodegenerative disease }\end{array}$ & $42(51 \%)$ & $25(60 \%)$ & $10(40 \%)$ \\
\hline Cerebral palsy & $6(7 \%)$ & $4(10 \%)$ & $2(8 \%)$ \\
\hline History of abdominal surgery & $21(25 \%)$ & $8(19 \%)$ & $6(24 \%)$ \\
\hline
\end{tabular}

AGGIR: Geriatric Autonomie Groups Resources Needs

${ }^{*} p<0.05$ 
Table 2: Surgical procedures

\begin{tabular}{|c|r|}
\hline Surgical procedure & Number of patients \\
\hline Emergency surgery & 7 \\
\hline Sigmoid resection plus primary colo-colic anastomosis & 5 \\
\hline Hartmann's procedure & 2 \\
\hline Elective surgery & 25 \\
\hline Sigmoid resection plus primary colo-colic anastomosis & 21 \\
\hline Hartmann's procedure & 4 \\
\hline
\end{tabular}


Table 3: Surgical complications using the standardized reporting system of ClavienDindo

\begin{tabular}{|c|c|c|}
\hline Post-operative complications & Emergency surgery $(n=7)$ & Elective surgery $(n=25)$ \\
\hline $\begin{array}{l}\text { Grade I } \\
\text { Any deviation from the normal } \\
\text { postoperative course without the need for } \\
\text { pharmacological treatment or } \\
\text { surgical, endoscopic, and radiological } \\
\text { interventions }\end{array}$ & & $\begin{array}{l}\text { Nosocomial pneumonia } \\
(n=1) \\
\text { - Postoperative ileus } \\
(n=1) \\
\text { - Wound dehiscence } \\
(n=1)\end{array}$ \\
\hline $\begin{array}{l}\text { Grade II } \\
\text { Requiring pharmacological treatment } \\
\text { with drugs other than such allowed for } \\
\text { grade I complications }\end{array}$ & & - Hemorrhage $(n=2)$ \\
\hline $\begin{array}{l}\text { Grade III } \\
\text { Requiring surgical, endoscopic or } \\
\text { radiological intervention }\end{array}$ & $\begin{array}{ll}- & \text { Evisceration }(\mathrm{n}=1) \\
\text { - } & \text { Anastomotic stenosis } \\
& (\mathrm{n}=1)\end{array}$ & $\begin{array}{ll}\text { - } & \text { Eviscerations }(n=2) \\
\text { - } & \text { Acute peritonitis }(n=1) \\
& \text { Abdominal wall } \\
\text { - } & \text { Adhematoma }(n=1) \\
& \text { obstruction }(n=1)\end{array}$ \\
\hline $\begin{array}{l}\text { Grade IV } \\
\text { Life-threatening complication requiring } \\
\text { IC/ICU management }\end{array}$ & $\begin{array}{l}\text { - } \text { Cardiogenic pulmonary } \\
\text { edema }(n=1)\end{array}$ & \\
\hline Grade V & - Death $(n=2)$ & - Death $(n=2)$ \\
\hline
\end{tabular}


Table 4: Characteristics in recurrence and non-recurrence groups among nonoperated patients

\begin{tabular}{|l|l|l|l|}
\hline & Recurrence (n=21) & $\begin{array}{l}\text { Non-recurrence } \\
\text { (n=19) }\end{array}$ & p \\
\hline Mean age \pm SD (years) & $78 \pm 13$ & $74 \pm 12$ & ns \\
\hline Male & $14(67 \%)$ & $13(68 \%)$ & ns \\
\hline Institutionalized & $14(67 \%)$ & $11(58 \%)$ & ns \\
\hline Severe loss of autonomy & $10(48 \%)$ & $9(47 \%)$ & $n s$ \\
\hline Neurological impairment & $14(67 \%)$ & $13(68 \%)$ & $n s$ \\
\hline $\begin{array}{l}\text { History of abdominal } \\
\text { surgery }\end{array}$ & $5(24 \%)$ & $2(11 \%)$ & \\
\hline
\end{tabular}

